\title{
Dynamic Modelling of Molten Salt Central Receiver Systems
}

\author{
Robert Flesch*. Daniel Maldonado Quinto.** Peter Schwarzbözl *** \\ *German Aerospace Center (DLR), Juelich, 52428 \\ Germany (Tel: +49-2203-601-4172; e-mail: robert.flesch@dlr.de). \\ **German Aerospace Center (DLR), Cologne, 51147 Germany (e-mail:daniel.maldonadoQuinto@dlr.de) \\ ***German Aerospace Center (DLR), Cologne, 51147 Germany (e-mail:peter.schwarzboezl@dlr.de).
}

\begin{abstract}
Keywords: Solar energy, concentrated solar power, central receiver, molten salt, finite element method, coupled simulation, control system
\end{abstract}

\section{INTRODUCTION}

Molten salt central receiver (MSCR) systems are a very promising option for the large-scale production of electricity from solar radiation. A central receiver system consists of a field of thousands of mirrors which reflect the sunlight to the top of a tower, at which the receiver is located. The receiver is built of tubes where molten salt is flowing through as the heat transfer fluid. The salt is heated up due to the concentrated solar radiation. The hot salt can be easily stored in large unpressurized tanks driving a convectional steam plant afterwards. The efficiency and the easy storage option have made the MSCR system to the predominant concentrating solar technology in the recent years.

Like every other technology which uses direct solar radiation, MSCR systems have to deal with a highly dynamic resource. Clouds which move over the heliostat field and shade heliostats result in a highly non-uniform and transient flux density distribution on the receiver surface. The task of the control system is to ensure a safe and efficient operation under the described dynamic boundary conditions. Due to the usage of molten salt used as fluid in the receiver the safety aspect during operation is especially challenging. Temperatures below $240^{\circ} \mathrm{C}$ must be avoided because of crystallization in the tubes (Zavoico, 2001). If not radiated for a short period, the system has to be drained. The upper temperature is restricted to approximately $600^{\circ} \mathrm{C}$ to avoid degradation of the salt and corrosion of tubes (Zavoico, 2001). With regards to the typical design temperature range from $290^{\circ} \mathrm{C}$ to $565^{\circ} \mathrm{C}$, the control system has to regulate the temperature with just a small deviation.

The DLR has created a dynamic simulation environment for MSCR systems which includes a detailed model of the heliostat field and the receiver. The simulation environment can be used to simulate and evaluate control strategies of the receiver system under realistic boundary conditions.

First, we briefly describe the approach and provide some validation data. Then, initial results of our current work are shown and an outlook to our planned activities is given.

\section{METHODS}

A MSCR system can be divided into subunits. In the present analysis the heliostat field and the receiver are the two units of interest. For a realistic analysis of the receiver dynamics it is necessary to have a model of the heliostat field which calculates the flux density distribution on the receiver. We used the in-house developed ray tracing tool STRAL (Belhomme et al, 2009) for this task. The receiver, however, is modelled by using the modelling language Modelica within Dymola. Both tools are connected with the third party tool TISC (Kossel et al, 2006), which exchanges data in a predefined synchronization rate. In the following the two models are described in little more detail.

\subsection{Heliostat field model}

STRAL is a simulation tool which can be used to calculate the flux density produced by a heliostat field on any arbitrary surface in high calculation speed. In our case, the cylindrical or polygonal shape of the receiver is used. STRAL has proven its high accuracy in several tests (Belhomme et al, 2009). To reproduce the flux of an existing field, heliostat surface information obtained from deflectometry measurements can be included (Belhomme et al, 2009). STRAL itself does not offer a method to include shading data of clouds, but it can be controlled from Matlab: in Matlab a tool was created which can be used to include DNI maps which are created as described in (Schenk et al, 2015). In the model a heliostat is switched off if the flux density in its centre falls under a given threshold. This is a simplification as in reality a heliostat can obviously be partly shaded, but the influence is assumed to be small in a field with typically several ten-thousands of heliostats.

\subsection{Receiver model}

The model of the receiver is implemented in Dymola with the modelling language Modelica. A receiver consists of panels through which the fluid flows sequentially. The panels are built of parallel tubes. To reduce the computational effort in the simulation several tubes can be bundled and represented by a single tube which is simulated. The fluid in the tubes is 
discretized one dimensionally with a finite volume approach using a staggered grid. The tube is divided in a front side and back side element. To calculate the temperature of the front element the differential equation

$$
\begin{aligned}
& \pi \Delta z k\left(\left(T_{\mathrm{O}}-T_{\mathrm{C}}\right) / \ln \left(d_{\mathrm{O}} / d_{\mathrm{C}}\right)-\left(T_{C}-T_{I}\right) / \ln \left(d_{\mathrm{C}} / d_{\mathrm{I}}\right)\right) \\
& +A_{\mathrm{FB}} 2 k /\left(d_{C} \pi\right)\left(T_{\mathrm{B}}-T_{\mathrm{C}}\right)=m c \partial T_{C} / \partial t
\end{aligned}
$$

is solved with the mass of the element $m$, the heat capacity $c$, the length $\Delta z$, the conductivity $k$, the contact surface between front and back $A_{\mathrm{FB}}$ and the temperature $T$ and diameter at the outer (O), central (C) and inner (I) position. As boundary for the outer temperature the relation

$$
d_{O} \Delta z\left(a I-\varepsilon \sigma\left(T_{O}^{4}-T_{\infty}^{4}\right)-\alpha\left(T_{O}-T_{\infty}\right)\right)=\pi \Delta z k\left(T_{O}-T_{\mathrm{C}}\right) / \ln \left(d_{\mathrm{O}} / d_{\mathrm{C}}\right)
$$

is used with the absorptivity $a$, the emissivity $\varepsilon$, the convective heat transfer coefficient $\alpha$, the incoming radiation $I$ and the ambient temperature $T_{\infty}$. The boundary for the inner temperature is similar, except it connects the heat transfer through the tube to the fluid temperature with a heat transfer correlation. The equation for the backside element is similar to (1) and uses the same inner boundary. The outer surface is assumed to be adiabatic.

Validation was performed with more detailed CFD and FEM simulations and additionally with experimental data as described in Flesch et al (2017). A comparison of the fluid temperature at several locations in the receiver for one case is given in Fig. 1. The model predicts the dynamics of the temperature very well.

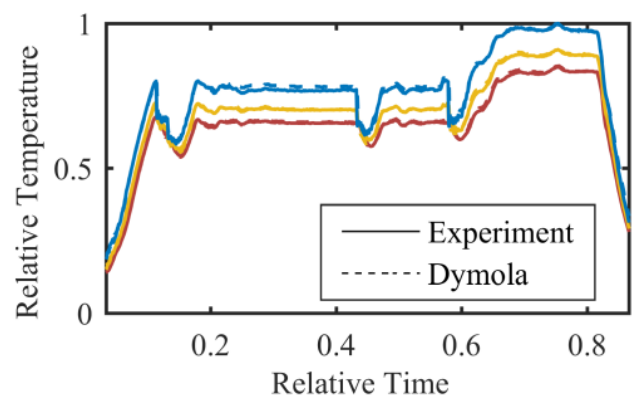

Fig.1. Validation with experimental data. The different colours indicate different position in the receiver.

\section{RESULTS}

As example simulation result the temperature response of the system on a cloud shading the southern part of the heliostat field of a plant located in South Africa is shown in Fig 2. The cloud moves from west to east. In the plots the results for three different control systems is shown: the first system corresponds to the one used in the Solar Two plant (Pacheco, 2002). It includes a so-called cloud standby (CSB) which increases the mass flow in case of a skewed flux distribution caused by clouds. The second system equals the Solar Two approach without CSB. The third system is as well similar to the Solar Two system but instead of a CSB it uses limits for the mass flow which are calculated from a model which uses an estimate of the current radiation on the receiver. The CSB in the Solar Two system is activated little too late to fully prevent the system from excessive temperatures, though it does avoid hazardous temperature peaks as one can see in case of the deactivated cloud standby. The system with the limits based on the current conditions performs better during cloud entry, but temperature overshoots when the cloud leaves. In that situation the control system requests a mass flow which is higher than the maximum mass flow of the system. This can be prevented by increasing the maximum mass flow rate or by using some kind of cloud forecast. Further results will be shown on the conference.
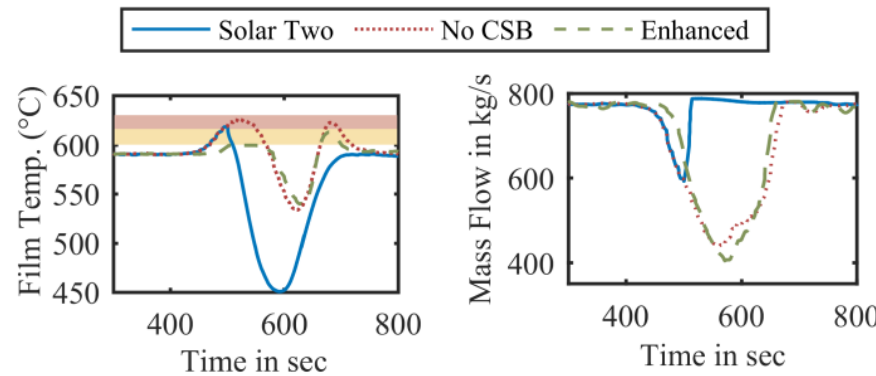

Fig. 2. Film temperature and mass flow of the receiver during cloud passage: The yellow colour indicates the temperature range which is allowed for short period. A temperature within the red range should be strictly avoided.

\section{SUMMARY AND OUTLOOK}

A coupled simulation approach has been developed to simulate the dynamics of a MSCR system e.g. during clouds. The state-of-the-art control system as used in the Solar Two plant with and without CSB was analysed and an enhanced system developed based on the lessons learned. In a recently started project we work on further improvements in the control of the normal operation by using a model predictive control. Besides we are working on an operation assistant system, which aims to improve and support the operators during receiver start-up and shutdown.

\section{REFERENCES}

Belhomme, B., Pitz-Paal, R., Schwarzbözl, P. and Ulmer, S. (2009). A New Fast Ray Tracing Tool for HighPrecision Simulation of Heliostat Fields. Journal of Solar Energy Engineering, 131 (3), 031002.

Flesch, R., Högemann, D., Hackmann, J., Uhlig, R., Schwarzbözl, P., Augsburger, G. and Clark, M. (2017). Dynamic modeling of molten salt power towers. AIP Conference Proceedings, 1850, 030016.

Kossel R., Tegethoff W., Bodmann M. and Lemke N. (2006). Simulation of complex systems using Modelica and tool coupling. $5^{\text {th }}$ Modelica Conference, 2, 485

Pacheco J.E. (2002). Final Test and Evaluation Results from the Solar Two Project, Sandia National Laboratories, Albuquerque, New Mexico and Livermore, California.

Schenk, H., Hirsch, T., Wittmann, M., Wilbert, S., Keller, L. \& Prahl, C. (2015). Design and Operation of an Irradiance Measurement Network. Energy Procedia, 69, 2019.

Zavoico A.B. (2001). Solar Power Tower Design Basis Document, Sandia National Laboratories, Albuquerque, New Mexico and Livermore, California. 